3. When determining high percentages of nitric nitrogen by the modified Gunning method, it is necessary either to continue the boiling for some time after the contents of the flask have become colorless, or to use permanganate to complete the action.

MarylaND ACRICULTURAL. Collece,

COLLEGE PARK, MI).

February 20,1895

\title{
ON CONDENSATION; AND ESPECIALLY ON THE CONDENSATION OF NITRIC ACID.'
}

BY EDWARD HART

Received January 7,1895

THE ideal condenser, economically considered, is the one simplest in construction, most accessible for repairs or other purposes, and which, with a given efficiency, requires the least cooling liquid. The old-fashioned worm is certainly far removed from this ideal. The Liebig's condenser is a nearer approach. If the space between the inside and outside tube in Liebig's apparatus is made narrow enough it is possible to effect complete condensation in a relatively short tube, and to raise the cooling liquid to boiling temperature. At first sight it would seem that this gives a maximum efficiency; but it does not. If the water used as cooling liquid has, at the start, a temperature of $0^{\circ}$, and, as it issues from the condenser, a temperature of $100^{\circ}$, the heat absorbed by a given weight of water is approximately Ioo units. If, however, the cooling liquid can also be made to evaporate, the heat absorbed is much larger in amount, and is equal to roo units plus the amount required to evaporate it ( 526 units). This makes in all 626 units, or an efficiency six times as great. In the Liebig's condenser, also, the liquid condensed is cold or nearly so. In many cases this is not necessary and then an additional loss is sustained.

In the apparatus which I shall describe a very brief consideration will show that the maximum of efficiency may be attained. For, first, the cooling water is evaporated; second, the condensed liquid is boiling hot.

This condenser I have used in several modified forms adapted

1 A paper with this title was read at the World's Congress of Chemists, Chicago, August 26,1893 . The present paper has been revised to accord with more recent experieuce and practice. 
to various special purposes, among others, to the cooling of ammonia gas and the condensation of nitric acid.

In its simplest form, as used for preparing distilled water for example, the apparatus consists of a pipe with return bands placed one above the other, so that the vapor passes through the pipe in an upward direction, first right then left then right again, and so on, the bends rising one directly over another.' This pipe should be so large in diameter that the liquid may flow down in the lower part of the tube while the vapor is passing upward above it. For the same reason each bend of the pipe should have a slight rise so that the water may run down more rapidly. At the lower end the pipe should be enlarged and provided with an inverted siphon to act as a trap and carry off the condensed water. If, now, steam be passed up the pipe and water showered over the topmost bend, the water will, as it trickles down, become heated and evaporate. It is clear that by properly regulating the flow of steam and of water, we may secure complete condensation of the former and complete evaporation of the latter; at the same time the condensed water as it passes from the trap will have the boiling temperature. The cooling effect, if the apparatus is placed in the open air, is greater even than theory would predict for we have the additional cooling effect of the air. I have used this apparatus also for the separation of water vapor from ammonia gas, and for cooling the latter previous to condensing it. The conditions here are much the same as in the apparatus for distilled water. It is necessary to keep the condensed water at boiling heat to prevent reabsorption of ammonia, and in practice we find that very little ammonia is contained in this condensed water. The inclined tube acts besides as a very effective washer for the gas, completely removing any impurities mechanically carried over from the still. If it is desired to cool the condensed liquid, this is best done in a smaller apparatus of the same sort in which the current of liquid passes in an upward direction.

In the condensation of nitric acid the substances which can be used for the condenser are glass and stoneware, and it is therefore best to modify the apparatus somewhat, for the sake of sim-

\footnotetext{
1 I have previously described a form of this apparatus which may be used for fractional distillation. See Am. Chem. J.,6, 178 .
} 
plicity and for decreasing the pressure in the pipes, which causes loss and annoyance by leakage through joints, and pinholes in the stoneware. With this in view the stream of vapor has been subdivided by passing it through a number of glass tubes with slight fall sufficient to allow the condensed liquid to flow back into the receiver. In the apparatus shown in the figure, the

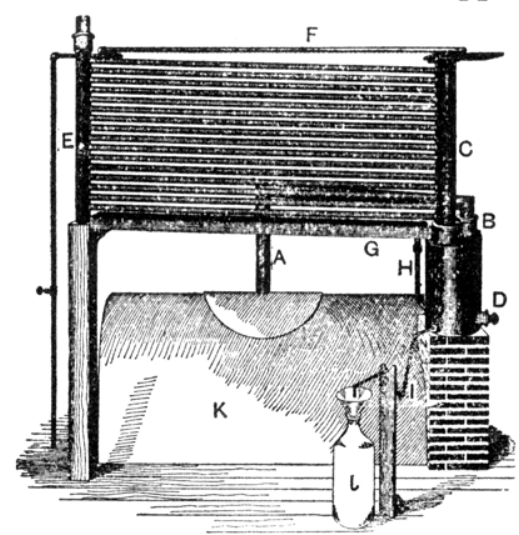
upright tubes at either side are made of stoneware, the connecting tubes are of thin glass. The pipe $\mathrm{A}$, made of stoneware, carries the nitric acid vapors from the retort into the pot $\mathrm{B}$ provided with a stopper, D, which is taken out if frothing should occur and allows the froth to escape without danger of filling the condenser. The vapors pass up into $\mathrm{C}$ and are distributed through the glass tubes luted into it. The condensed acid runs back and is discharged through the glass trap I into the container $\mathrm{J}$.

The use of the glass tube is of great advantage since the color and amount of acid can be seen throughout the distillation and the firing regulated accordingly. From the pot the vapors ascend into the stoneware pipe and pass through the nearly horizontal glass pipes let into it into another similar stoneware tube on the left, from which the chlorine and lower oxides of nitrogen escape to the chimney or tower. These tubes are slightly inclined, and the acid condensing runs back into the pot. In running back it becomes very hot by contact with the vapors coming over and is deprived of the oxides of nitrogen. Condensation is effected by running water over the glass tubes from the perforated pipe above.

This apparatus is, to a certain degree, self-regulating. It never happens that the tubes condense the gas in equal amount. One of them is thinner or a little wider, and as condensation is more rapid the flow of gas into the tube is more rapid. But, in 
any event, the pressure is equal in all the tubes, and only when the distillation is hurried too much will any uncondensed vapor pass through. There are fifteen tubes to each condcnser about an inch in diameter and six feet long.

Two of these condensers have been in use for nearly two years at the works of Baker and Adamson, Easton, Pa., and the system has, therefore, had a thorough test. The retorts used here are cylindrical, as shown in the cut, and are made entirely of cast iron with iron heads. The niter-cake is drawn while fluid. These retorts each hold a charge of $\mathrm{r}, 000$ pounds sodium nitrate. They are charged at $7 \mathrm{~A}$. M. and the operation finished at 3. P M., a total of eight hours. The best practice by the Griesheim system is, ordinarily, a charge of eight cwt. in twenty-four hours; under favorable conditions, and with a good fireman, sixteen hours are needed.

The floor-space required in this apparatus is reduced to a minimum. The condensers are, as shown in the cut, placed over and above one side of the brick arch which covers the cylindrical retort, so that absolutely no additional floor-space is required, all that is needed being sufficient room to pass conveniently between the retorts.

One man can run several retorts. All the assistance needed is that of a helper in discharging the retorts and in emptying the salt cake from the pans. These operations will require, perhaps, half an hour each.

In another place I have already ( $J$. Anal. Appl. Chem., 5, 382 ) pointed out the advantages of giving a cylindrical form to the retort, which requires less floor-space, less cost for masonry, and is less expensive in coal consumption. The form I have used is very much superior to, and quite different from, any of the patterns shown by Guttmann ( $J$. Soc. Chem. Ind., 12, 203). In brief, this new form of condenser has the following good points :

I. It gives great efficiency with small first cost.

2. It requires but little water.

3. It requires but little floor-space.

4. It reduces the pressure and so reduces leakage.

5. It is easily and cheaply repaired. 